\title{
PAIXÃO PARTILHADA E PARTICIPATIVA - O CASO DO FUTEBOL
}

\author{
Shared and participative passion- \\ The case of football \\ Arlei Sander Damo*
}

\begin{abstract}
RESUMO
Este artigo trata da relação entre emoção e política no espectro do futebol de espetáculo tendo como ponto de partida as investigações etnográficas realizadas entre torcedores e profissionais deste esporte. Serão recuperados conceitos forjados pelo autor no decorrer destas investigações, evidenciando a dimensão política e emotiva na produção, expressão e negociação das identidades no espaço do futebol.
\end{abstract}

Palavras-chave: futebol; identidade; emoção; política; clube; nação.

\begin{abstract}
This article treats the relationship of emotion and politics on the spectrum of the soccer spectacle taking as its starting point the ethnographic research conducted between professionals and supporters of this sport. Will be recovered concepts forged by the author throughout this research, emphasizing the political and emotional dimension in the production, expression and negotiation of identities within soccer.
\end{abstract}

Key-words: football; identity; emotion; politics; club; nation.

\section{Introdução}

A proposta deste dossiê, veiculando sentimento e política no espectro do futebol, vem ao encontro da minha produção intelectual. Esta

* Professor do PPG Antropologia Social/UFRGS. 
é uma coincidência agradável, pois me permite reafirmar e acrescentar certos pontos de vista. Mas é também incômoda, pois me instiga a revisitar minha trajetória de pesquisa e isso pode dar a impressão de presunção. Correr este risco se justifica em razão do papel importante desempenhado pela etnografia na elaboração e no refinamento da noção de pertencimento clubístico, a partir da qual busquei um diálogo entre o campo da política e o campo das emoções. No âmbito da antropologia, existem múltiplas formas de entendimento do que seja a etnografia e qual o seu papel. Partilho com aquelas que pensam a etnografia para além de uma estratégia para a obtenção de dados, definindo-a como um contexto de diálogo e experimentação, no qual interpretações consolidadas no espectro das teorias são confrontadas com aquelas produzidas pelos "nativos", que passam, assim, da condição de informantes à de interlocutores.

A forma como fui articulando as noções de sentimento e política tem muito a ver com esta negociação permanente entre teorias socioantropológicas e interlocuções etnográficas. O resultado, inacabado e, por certo, prenhe de lacunas, é, no entanto, sugestivo de que certas teorias, de ampla utilização pela bibliografia especializada, têm limites bem claros. No que concerne à política, descarto desde logo a teoria da alienação, por razões já explicitadas por outros teóricos, incluindo-se a mais grave, de que ela não cumpre o elementar de uma teoria antropológica, por se negar a reconhecer como legítimos os significados socialmente produzidos pelos agentes sociais.

Uma vez descartada a teoria da alienação, e isso parece ser um fato generalizado no espectro das ciências sociais e da historiografia brasileiras, o que se observa não é a produção de teorias concorrentes, mas um silêncio quase absoluto. Aqui e ali alguns autores têm procurado tocar na questão, mas ainda há muito a ser feito. No âmbito das ciências sociais que no Brasil se articulam, mal ou bem, em torno das áreas da sociologia, da ciência política e da antropologia -, contrasta o interesse relativamente bem consolidado pela temática esportiva no âmbito da antropologia e, em menor proporção, da sociologia, enquanto ela permanece estranha aos cientistas políticos. Olhando-se para o conjunto da produção nesta área, e aqui me atreveria a incluir também a historiografia, nota-se que o tema da política é ainda pouco explorado. Escassos trabalhos tocando nas questões que dizem respeito às instituições esportivas, à produção e reprodução da 
classe dirigente, às dinâmicas do poder - nenhum trabalho de fôlego sobre eleições em clubes de futebol, por exemplo.

Todavia, se o cerne da política institucional não foi ainda problematizado devidamente, não se pode dizer que a questão da política não esteja presente em trabalhos que tratam de outros agentes do campo futebolístico, como é o caso dos torcedores. É claro que a noção de política operacionalizada por essas publicações é outra. Isso vale para os trabalhos sobre torcidas organizadas, mas também para aqueles acerca do público em geral, como é o caso da minha produção. Pelo menos neste último caso, a noção de política é operacionalizada de forma quase artesanal. Alguém poderá me acusar de desviar a discussão do debate teórico, quando na verdade o objetivo é trazer para o debate as noções de política acionadas pelos agentes em campo, na direção de uma teoria etnográfica da política. ${ }^{1}$

Tanto neste texto quanto nas pesquisas que estão na sua origem, procuro evitar a aplicação de conceitos exóticos que, forjados à distância do espaço esportivo, pudessem ser usados para interpretá-lo sem a devida mediação. O universo social do esporte e mesmo o do futebol é vasto o suficiente para oferecer evidências para uma série de teorias ou tornar operacionalizáveis muitos conceitos importados de outras áreas. O melhor a fazer é não adotar analogias e correlações genéricas, mas antes avançar a partir de interpretações que deem conta da especificidade do campo. Isso não impede, por certo, a apropriação de conceitos, mas exige que o processo seja criterioso. Em síntese, privilegio aqui a busca pela originalidade e especificidade das emoções experienciadas no espectro do futebol e, particularmente, daquele segmento voltado para o espetáculo. Pouco importa que não avance ao ponto de produzir uma "teoria das emoções".

Como dito anteriormente, recupero alguns elementos do trabalho de campo desenvolvido para a dissertação de mestrado, apresentada em $1998,{ }^{2}$ e da tese de doutorado, defendida em $2005 .{ }^{3} \mathrm{Na}$ dissertação, as

1 ABÉLÈS, Marc; JEUDY, Henri-Pierre. Anthropologie du politique. Paris: Armand Colin/ Masson, 1997.

2 DAMO, Arlei. Para o que der e vier: o pertencimento clubístico no futebol brasileiro a partir do Grêmio Foot-Ball Porto-Alegrense. Dissertação (Mestrado) - PPGAS/UFRGS. Porto Alegre, 1998.

3 DAMO, Arlei. Do dom à profissão: uma etnografia do futebol de espetáculo a partir da formação de jogadores no Brasil e na França. Tese (Doutorado) - UFRGS/PPGAS. Porto Alegre, 2005. (Disponível em: <http://www.biblioteca.ufrgs.br/Bibliotecadigital >). 
questões da identidade clubística, das tensões a respeito, dos vínculos dos torcedores a seus clubes, da educação, da sensibilidade e da expressão das emoções constituíam o objeto principal da investigação. Já a tese tratava da formação de jogadores e, a rigor, não necessitava retomar as questões supracitadas. Todavia, ao avançar com a etnografia, fui descobrindo que um dos aspectos importantes na formação dos jogadores, e que excedem os investimentos realizados nas técnicas corporais específicas, passava pela dimensão emocional e, mais especificamente, por um aprendizado de como lidar com a ansiedade e a pressão do público. A partir de certo momento, incorporei a hipótese de que a formação de jogadores, diria mesmo que a existência de uma carreira dessa natureza, não existiria sem que houvesse um público para valorizá-la, remunerá-la e exigi-la. Cada vez mais foi ficando claro que a formação de jogadores não poderia ser descolada das expectativas do público e, em se tratando de futebol, o público não é uma massa dispersa, antes comunidades de pertença bem arranjadas em torno dessas instituições denominadas clubes. Retornar ao clubismo foi, então, um percurso natural.

Neste texto em particular, trato de vários aspectos envolvendo a relação entre emoção e política presentes no conceito de pertencimento clubístico. O ponto de partida é um dos capítulos da tese que não foi integralmente aproveitado por ocasião da conversão desta em livro. Trata-se do segundo capítulo, denominado "A trama simbólica das emoções clubísticas: uma contribuição à compreensão do gosto pelo futebol de espetáculo", ${ }^{4}$ que na origem estava subdividido em três partes, sendo que duas delas não foram utilizadas ou o foram apenas rapidamente quando da preparação do livro. Esse material de origem foi revisado e ampliado, mas como se trata de um tema sobre o qual me ocupo há vários anos, não será surpresa que, aqui e ali, reapareçam argumentos veiculados também em outros textos de minha autoria. Dadas as particularidades do texto, não havia como evitar certas autorreferências. Espero que fique claro que elas não visam a uma apologia do autor a sua própria obra, algo francamente repulsivo, antes uma estratégia para auxiliar o leitor que porventura deseje acessar os argumentos desenvolvidos de forma mais densa. 


\section{1 - Pertencimento clubístico}

Por muito tempo, inquietou-me o fato de encontrar em textos não acadêmicos as definições mais apropriadas para o sentimento de devoção aos clubes de futebol por parte dos torcedores. A convicção acentuou-se ao longo da pesquisa de mestrado em relação à qual o pertencimento clubístico constituiu-se no objeto central. Para ser franco, a noção de pertencimento clubístico foi forjada em meio à escrita da referida dissertação e talvez seja sua principal contribuição. Desde o princípio daquela investigação, trabalhei com o conceito de identidade social, tentando adequá-lo para o espaço do futebol, o que efetivamente não era um problema. Não me interessava tanto pela questão das torcidas organizadas, o foco principal das investigações na década de 1990, mas pela identificação dos torcedores com seus clubes num plano mais amplo. Por um lado, procurava resgatar as diferentes modalidades de vínculos, não apenas entre os torcedores e seus clubes, mas dos torcedores de um mesmo clube entre si, dos clubes com as cidades e regiões onde estão sediados ou, ainda, com categorias sociais mais alargadas, como raça e classe social, as mais recorrentes no contexto brasileiro - e não sem motivos. Por outro lado, havia a questão concernente ao sentimento que amalgama os torcedores a seus clubes, caracterizando tal modalidade de vínculo por uma forte conotação exclusivista (dito único e imutável), um tipo anacrônico se pensado em relação à modernidade e, sobretudo, à contemporaneidade, em que sobressaem as escolhas do tipo mutável, reversível, instrumental e assim por diante.

Ao direcionar o olhar para a questão dos vínculos clubísticos, independente de quais fossem, o jogo de futebol foi sendo desfocado. Este caminho gerou algumas vantagens e muitas desconfianças. Vantagens inegáveis por me distanciar do discurso midiático, sobretudo dos cronistas esportivos e dos historiadores amadores, que seguidamente confundem os investigadores das ciências sociais e os historiadores profissionais com suas categorias de apreciação estética, cuja realidade é preponderantemente discursiva. $\mathrm{O}$ deslocamento não teve a intenção de forjar uma modalidade de verdade para ser confrontada com sua antítese, mas reconhecer que existe uma diferença substantiva de propósitos entre a produção acadêmica e aquela dos cronistas, pois estes fazem parte do campo e têm por atribuição - no que concerne à divisão social do trabalho no âmbito do futebol de espetáculo - a produção 
de narrativas performáticas, no sentido de tornar os espetáculos ainda mais espetaculares, com o perdão da redundância. ${ }^{5}$ As desconfianças, algumas veladas outras manifestas, seriam pelo fato de retirar o jogo do cenário interpretativo, o que faço, por certo, algumas vezes, de forma estratégica. ${ }^{6}$ Em todo o caso, uma antropologia do esporte e do futebol será sempre uma antropologia, se é que foi bem feita. Arranjos demasiado heterodoxos produzem narrativas performáticas, por certo, mas pouco acrescentam em termos de compreensão dos significados do que quer que seja.

Indagando diretamente aos torcedores, não encontrei para minhas perguntas - mal formuladas, talvez - senão respostas lacônicas, óbvias ou redundantes: "gosto do Grêmio porque ele é azul"; "não sei o porquê, mas sempre gostei desse time"; "todos na minha família são colorados"; "para mim, o Grêmio é tudo" e, aquela que foi a gota d'água para repensar os procedimentos, "não sei como dizer! Ser gremista é experimentar todas as emoções. Ser gremista é ter orgulho de sê-lo". Esta última tornar-se-ia epígrafe de um dos capítulos da dissertação e a razão de tal escolha, bem me lembro, foi o fato de uma definição aparentemente tão evasiva ter sido extraída de uma redação classificada em segundo lugar num concurso realizado pelo próprio Grêmio, o que significava que ela dizia algo partilhado por outros gremistas. ${ }^{7}$

Durante a revisão bibliográfica da referida dissertação, fui colecionando, em contrapartida, frases que eu imaginara ouvir de meus informantes, em lugar de seus reiterados embaraços, evasivas e obviedades. Tais frases não eram de colegas antropólogos ou sociólogos, mas em grande parte retiradas de seus textos, nos quais eram referidas em citações, muitas delas em epígrafes, atribuídas a José Lins do Rego, Luiz Fernando Veríssimo,

5 A aproximação entre o campo esportivo e o campo artístico, a partir da contribuição bourdiana, sobre o mercado de bens simbólicos, e sobretudo da antropologia da admiração, de Nathalie Heinich, me fariam ratificar o acerto desta tomada de posição. Sobre isso, conferir DAMO, Arlei. Produção e consumo de megaeventos esportivos: apontamentos em perspectiva antropológica. Comunicação, Mídia e Consumo, v. 8, p. 67-92, 2011.

6 A mais reativa contraposição veio de José Miguel Wisnik, de quem efetivamente me diferencio no que tange à importância das categorias intrínsecas do jogo para entender a formação do público aficionado.

7 A presença do Grêmio, aqui, deve-se ao fato de que o trabalho de campo foi realizado no entorno deste clube. 
Carlos Drummond de Andrade, Nelson Rodrigues, Armando Nogueira e assim por diante. ${ }^{8}$

Os poetas e cronistas, com o domínio singular da palavra, textualizavam aquilo que meus informantes tinham dificuldade de expressar: suas emoções, sobretudo em narrativas individuais. De todas as anotações que colecionei, aquela que mais me impactou e da qual jamais me afastei foi de Carlos Drummond de Andrade, que reproduzo a seguir:

A estética do torcedor é inconsciente: ele ama o belo através de movimentos conjugados, astuciosos e viris, que lhe produzem uma sublime euforia, mas se lhe perguntam o que sente, exprimirá antes uma emoção política. Somos Fluminenses ou Vascos pela necessidade de optar, como somos liberais, socialistas ou reacionários. Apenas, se não é rara a mudança do indivíduo de um para outro partido, nunca se viu, que eu saiba, torcedor de um clube abandoná-lo em favor de outro. ${ }^{9}$

Drummond não apenas juntou futebol, emoção e política, senão que deslocou para o primeiro plano da relação a questão do engajamento. A ideia de que a escolha de um clube - Drummond usa "time" como sinônimo de clube - se assemelha à definição por um partido, no sentido de comprometimento com algo, foi de fato essencial na concepção da noção de pertencimento clubístico. Na verdade, o termo clube é um dos substantivos que vêm sendo usados mais ou menos em toda a parte para se referir ao coletivo agregado no entorno de objetivos comuns, mormente vinculados a atividades atinentes ao espaço-tempo do lazer e do entretenimento. $\mathrm{O}$ termo é de origem notadamente inglesa (club) e no Brasil pode ser substituído, sem prejuízo de sentido, por grêmio, associação, sociedade, entidade e assim por diante. A opção pelo termo clube - clubístico, clubismo e outros neologismos - não teve qualquer conotação extraordinária; foi apenas a opção que me pareceu mais conveniente pelo termo ser mais recorrente. Já a escolha do termo pertencimento mereceu uma atenção especial, pois o

8 Para uma lista das que considero mais expressivas, conferir DAMO, Arlei. Para o que der e vier..., 1998, p. 57-62.

9 ANDRADE, Carlos Drummond de. O mistério da bola. In: Fala amendoeira. Rio de Janeiro: Record, 1957. 
objeto principal na ocasião era designar uma modalidade de vínculo intensa, duradoura e exclusiva (ou próxima disso). Identidade também poderia ser um termo interessante, mas pertencimento me pareceu realmente forte, capaz de expressar um vínculo sentimental profundo, embora por vezes tido como inexplicável, entre um indivíduo e uma dada coletividade, tendo como mediador o clube.

Pertencimento clubístico foi, portanto, um neologismo forjado para dar conta de uma modalidade de vínculo identitário próprio à esfera do futebol, mas que poderia ser ampliado, pois, em países nos quais o futebol não é o esporte hegemônico, o clubismo pode estar vinculado a outras modalidades coletivas - ao beisebol, rúgbi, basquete etc. A noção prestou-se não apenas para produzir um distanciamento em relação às noções nativas correspondentes - torcer, gostar, amar, ser apaixonado etc. - mas para especificar, no espectro do torcer, um segmento de público militante, não necessariamente pela frequência aos estádios, nem mesmo pelo vínculo a grupos organizados, mas emocionalmente engajado a ponto de estender as emoções vividas no espaço-tempo do jogo para além dele. Ainda que usados seguidamente como sinônimos, torcer e pertencer já não são exatamente o mesmo.

É imprescindível, como escreveu Bromberger, estar engajado a uma das partes para vivenciar plenamente a excitação futebolística. " $\mathrm{C}$ 'est la passion partisane qui donne sens, sel et intérêt à la confrontation. [...] La partisanerie est la condition nécessaire pour assurer um maximum d'intensité pathétique à la confrontation". ${ }^{10}$ As sensibilidades e os juízos estéticos engajados podem variar em intensidade e forma, mas não serão jamais neutros, mesmo quando se passa do pertencimento clubístico ao pertencimento nacional, nos casos de enfrentamento entre equipes representando Estados-nações.

10 "A los hinchas italianos se los llama tifosi, y ésta es una palabra derivada de tifo, que significa apoyo, pero etimológicamente significa tifus, una enfermedad contagiosa, una de cuyas variantes se traduce en fiebre y agitación nerviosa. El tifosi es aquél que tomo la decisión de sentir plenamente la intensidad del drama convirtiéndose en actor (y no simple espectador) de una historia incierta que se construye ante sus ojos, y en cuyo desarrollo cree poder influir a través de una intensa participación corporal y vocal. Efectivamente, aquí, a diferencia de las películas y las piezas de teatro, las cartas no están echadas antes de la representación [...]". BROMBERGER, Christian. Significación de la pasión popular por los clubes de fútbol. Buenos Aires: Libros del Rojas/UBA, 2011. p. 22. 
Neste aspecto, há uma tentativa de ir além da teoria eliasiana, na qual é lançada a hipótese de que o público esportivo acorre aos eventos em busca de excitação, mas as razões dessa mobilização não são especificadas. Elias e Dunning ${ }^{11}$ recorreram, como tantos outros intérpretes das emoções esportivas, aos fundamentos da tragédia grega, supondo que há nos eventos esportivos um residual trágico: alternância de sentimentos que produzem emoções fortes, com intensa participação do público, instado a manifestar-se abertamente, mantendo certo limiar de controle. As emoções esportivas seriam do tipo mimético, experimentadas a partir de sentimentos despertados por "medo e compaixão ou ciúme e ódio por simpatia com os outros, mas de uma maneira que não é seriamente perturbante e perigosa [...]. Na esfera mimética são, por assim dizer, transpostos numa combinação diferente. Perdem seu ferrão". ${ }^{12}$ Com pequenas adaptações, pode-se substituir o termo esporte por teatro ou cinema e o dito mantém o sentido, o que indica claramente a sua perspectiva generalizante.

Em linhas gerais, a teoria eliasiana aplica-se ao esporte, mas, como dito acima, pouco contribui para o entendimento das especificidades, em especial dos diferentes sistemas simbólicos que dão suporte às emoções nos esportes que mobilizam extenso contingente de público. A propósito, Geertz $^{13}$ se serve de referências muito próximas das de Elias - inclusive na referência à Poética de Aristóteles - na interpretação da briga de galos balinesa. A teoria do processo de civilização, no espectro da qual opera a hipótese da busca de excitação controlada (mimética) promovida pelos esportes modernos, auxilia na compreensão da emergência do fenômeno esportivo, mas revela-se insuficiente para dar conta da progressiva autonomização do campo esportivo e, sobretudo, da constituição de públicos específicos, sobretudo para o caso do futebol.

Tomando-se, pois, a questão do engajamento como fulcral para entender a constituição do público no futebol de espetáculo, pode-se afirmar que existem, a rigor, duas estratégias principais, sendo que a cada uma delas

11 BROMBERGER, Christian. Football, la bagatelle la plus sérieuse du monde. Paris: Bayard Editions, 1998. p. 272-273. "É a paixão militante que dá sentido, sal e interesse pelo confronto [...]. A militância é a condição necessária para assegurar um máximo de intensidade emotiva no confronto" (minha tradução).

12 ELIAS, Norbert. Introdução. In: ; DUNNING, Eric. A busca da excitação. Lisboa: Difel, 1992. p. 124

13 GEERTZ, Clifford. A interpretação das culturas. Rio de Janeiro: Guanabara, 1989. 
corresponde um circuito de competições - e também de rivalidades, tensões e assim por diante. Um desses circuitos, que no presente é controlado econômica e politicamente pela FIFA e suas parceiras, se concentra, basicamente, em eventos nos quais competem equipes representando Estados-nações. Outro circuito, mais amplo e menos sujeito às ingerências da FIFA, mas ainda assim sob sua tutela, é composto pelos múltiplos certames de competições clubísticas - isso inclui desde uma competição continental, como a Champions League ou a Libertadores da América, até os campeonatos de futebol amador, restritos a cidades ou bairros.

A principal diferença entre esses dois circuitos é da ordem do simbólico, uma vez que diz respeito à modalidade de engajamento dos respectivos públicos. Em outras palavras, o combustível que move o circuito do nacionalismo advém da identificação dos torcedores com as equipes que representam a nação. Trata-se, portanto, de uma identificação que desliza do âmbito do nacionalismo para o futebol. $\mathrm{O}$ trabalho de identificação entre um pequeno coletivo - uma equipe de 11 atletas - e outro, muito extenso - integrado pelos que se reconhecem como membros de uma nação - é facilitado neste último caso. Todavia, não basta vestir o time de futebol com as cores da bandeira nacional para que a magia da identificação se produza. A relação metonímica não se produz naturalmente.

Converter uma equipe de jogadores num símbolo vivo da nação requer certo investimento, mas, como já disse muito apropriadamente Hobsbawm, ${ }^{14}$ não é algo que requeira estratégias mirabolantes. Basta observar como, às vésperas de competições importantes, como as copas do mundo ou as copas continentais - a Eurocopa, por exemplo -, existe uma intensa mobilização no sentido de promover este deslocamento de significado, da nação para a seleção, e vice-versa. Em geral, esta tarefa compete à mídia esportiva, sem que, no entanto, seja uma deliberação planejada. O fato é que a mídia tem razões próprias para promover tais eventos e seu trabalho converge em relação aos interesses das entidades promotoras - casos da FIFA, da UEFA e assim por diante. Com muita frequência, os intelectuais são mobilizados e a preferência recai, obviamente, pelos especialistas em temas relativos à formação da identidade nacional. Nos últimos anos, esses 
megaeventos receberam um forte incremento mercadológico, de modo que a publicidade comercial tem produzido peças visando vincular seus produtos aos sentimentos nacionalistas com a expectativa de alavancar as vendas e, ao proceder dessa forma, acabam por suscitar e fortalecer tais sentimentos. Em países como o Brasil, que carece de eventos e heróis capazes de unificar e condensar o pertencimento nacional, o time de futebol organizado para as copas e outras disputas do gênero acaba cumprindo esta função, razão pela qual os brasileiros param para assistir aos jogos, enquanto o dia alusivo à independência do Brasil é tratado como um feriado convencional - afora os desfiles militares, que ganharam impulso durante a ditadura, o que é uma contradição, pois a independência não custou uma única gota de sangue.

Em certas ocasiões, pode haver o envolvimento do Estado com esses megaeventos e a festa, que deveria ser laica, acaba gerando controvérsias. Um exemplo marcante é caso da Copa de 1978, organizada e vencida pela Argentina, à época governada por uma ditadura militar sanguinária, que se aproveitou da ocasião para se promover. A estratégia pode ter dado resultados imediatos, mas estes não impediram o esfacelamento da ditadura poucos anos depois. Passadas três décadas, aproximadamente, os argentinos estão promovendo o julgamento dos militares acusados de tortura e morte naquele período, ao mesmo tempo em que ressignificam a conquista de 1978. Como mostrou o antropólogo Archetti, ${ }^{15}$ no presente atribui-se àquela conquista uma coloração turva, a ponto de alguns dos jogadores que estiveram em campo sentirem-se envergonhados. $\mathrm{O}$ mesmo equivale para os torcedores, pois, embora muitos tenham saído às ruas para comemorar a conquista - entre eles havia os que aproveitaram também para protestar -, no presente é difícil encontrar quem admita que o fez.

Paralelamente ao circuito movido pelo nacionalismo, existe aquele integrado pelos clubes. Na verdade, são múltiplos circuitos, em geral consolidados a partir de fronteiras continentais, nacionais, regionais e até mesmo locais, conquanto estes últimos fiquem à margem da espetacularização. À diferença do circuito do nacionalismo, que se beneficia de uma identificação já estabelecida no âmbito do nacionalismo de Estado, a produção de identidades no espectro do clubismo é um processo mais complexo,

15 ARCHETTI, Eduardo. "Argentina 1978 and after: Military nationalism, football essentialism, and moral ambivalence”. Exposição realizada no XXVII Encontro Anual da ANPOCS, Caxambu (MG), 22 a 26 de outubro de 2003. 
pois os clubes são, em geral, entidades laicas. Empregando-se o mesmo processo do nacionalismo, chega-se, facilmente, a identificar um time com uma empresa, uma escola, um partido político, uma causa, uma cidade e assim por diante. Todavia, os chamados grandes clubes, que integram a elite dos circuitos nacionais, lograram extrapolar tais fronteiras, drenando para seu entorno pertencimentos bastante heteróclitos e ordenando-os de modo a produzir uma identidade própria. Se observarmos as identidades e as diferenças que constituem as rivalidades no clubismo, veremos o quanto elas estão impregnadas por elementos pinçados do espectro mais amplo da sociedade, tensões que são drenadas para as arquibancadas dos estádios, tornando os eventos futebolísticos um espetáculo que extrapola a dimensão esportiva. A ideia de que certos enfrentamentos dramatizam os dilemas sociais é amplamente compartilhada por todos aqueles que se debruçam sobre o tema no campo das ciências sociais.

O clubismo é, pois, uma ampla trama social e cultural. Nada impede que se trate a dimensão simbólica dessa trama como uma modalidade de totemismo moderno, com a ressalva expressa de que esta não é a única possibilidade de abordá-lo. Duas ponderações breves são aqui necessárias. ${ }^{16}$ Em primeiro lugar, tratar o clubismo como um totemismo não é uma antropologia às avessas, pois não há pretensão de explicar o complexo pelo simples. O que está no cerne do totemismo, enquanto conceito, é uma modalidade de representação coletiva articulada em forma de sistema. A escolha dos totens, que certas sociedades fizeram recair sobre espécies animais, é uma arbitrariedade cultural, razão pela qual os clubes de futebol podem ser aqui tomados como totens, como equivalentes a gaviões, águias, urubus e assim por diante. Toledo ${ }^{17}$ formulou uma versão de totemismo futebolístico brasileiro tomando como ponto de partida os animais escolhidos pelos torcedores como símbolos dos clubes - gavião/Corinthians, macaca/ Ponte Preta, porco/Palmeiras, urubu/Flamengo, galo/Atlético Mineiro etc. - limitando-se, no entanto, em apresentar a diversidade e justificar as identificações, interpretando-as como marcas diacríticas. $\mathrm{O}$ fato é que os animais ou personagens - saci/Inter, mosqueteiro/Grêmio etc. - servem

16 Para uma arguição mais completa a este respeito, consultar DAMO, Arlei. Do dom à profissão..., 2005, p. 63-66.

17 TOLEDO, L. Henrique. Torcidas organizadas. Campinas: Autores Associados, 1996. p. $52-73$. 
como símbolos de identificação, tal qual a camiseta, o boné, a bandeira ou qualquer vestimenta nas cores do clube. Nesse caso, são elementos visuais de mediação entre os torcedores e os clubes ou dos torcedores entre si pode-se pensar também em outros elementos de mediação não visuais, como cânticos e xingamentos. Em que pese um porco representar o Palmeiras, permanece em aberto a questão fundamental: o Palmeiras representa o quê? $\mathrm{Ou}$, por outra, o que significa ser palmeirense?

Ao invés de pensar que o jogo cria um público, por que não pensar que o público cria o jogo? E isto em dupla perspectiva: a partir daquilo que o público acrescenta ao jogo, em termos de expectativas, de comentários, de fantasias e assim por diante; e a partir daquilo que o público aficionado fez, ao longo de décadas, para tornar os jogos tão absorventes, repletos de virtuosismos, enfim, espetaculares. A performance dos jogadores não faz sentido separada do contexto do jogo, pois, no espectro do futebol de espetáculo, um jogo não é apenas o confronto de duas equipes, mas de comunidades de sentimento pontualmente representadas. Tais confrontos, pelo menos no presente, não se dão aleatoriamente, mas no interior de circuitos previamente articulados, chamados de campeonatos. Esses campeonatos são conformados por fronteiras - geográficas, econômicas etc. - e, o que é mais importante, parte do envolvimento do público tem a ver com os dilemas, as tensões, enfim, com os sentidos forjados no âmbito dessas fronteiras.

A questão da identidade ou, como preferimos na antropologia, das identidades, está profundamente vinculada ao futebol. Isto se deve, em parte, ao fato de esta questão - que embora clássica, se renova de forma surpreendente - ser fulcral para a compreensão de qualquer dinâmica de grupo. De outra parte, o espaço do futebol, em particular aquele voltado para o espetáculo, oferece-se como uma fonte generosa de questões a serem investigadas, pois nele são extensos e multifacetados os arranjos em termos de identidades e alteridades. A estrutura agonística do jogo, que pressupõe uma disputa bem demarcada entre um eu (ou nós) e um outro (ou outros), favorece, sobremaneira, a instauração da identificação e da diferenciação. Ainda mais que um jogo, como o de futebol, é um rito do tipo disjuntivo, no qual os contendores lutam para promover uma cisão entre vencedores e vencidos. Mas não se deve esquecer que uns e outros são partes indissociáveis da dinâmica do jogo, pois basta que um deles se negue a cumprir o papel que lhe é estruturalmente designado - deixar de atacar ou, o que é 
pior, de defender - para que o jogo perca o sentido. Adversários de um jogo são, sob este ponto de vista, parceiros de um evento. Afinal, o jogo suscita a presença de um outro contra quem, mas também com quem, se joga.

No universo do futebol de espetáculo, a questão da representação se coloca abertamente como um drama aos apreciadores e um problema interessante de ser investigado do ponto de vista antropológico. Diferentemente do engajamento elementar ao jogo, requisitado por todas as modalidades de práticas esportivas assentadas sobre a estrutura agonística, incluindo-se o jogo de cartas, no caso do espetáculo temos um engajamento secundário, cuja dimensão circunstancial se sobressai em relação à estrutura. No segundo caso, os componentes políticos tornam-se mais evidentes, pois a ideia de representação implica, necessariamente, mediação e, portanto, negociação. Muito embora a vitória seja um componente importante na afirmação de uma equipe ou de um jogador frente aos torcedores de clube ou seleção, a ideia do que seja uma boa ou má representação excede, consideravelmente, a questão dos resultados. A dedicação, a coragem, a bravura, em uma só palavra, a entrega, é também valorizada, mesmo na derrota.

Assim como existe uma história dos livros e outra das práticas de leitura, existe uma história dos jogos e deveria ter outra de como os torcedores são envolvidos neles. Para que possamos reconstituir as práticas do torcer - o que implica perguntar por quem, como, onde, com quem e para quem -, é preciso alargar nosso horizonte compreensivo acerca dos significados do pertencimento, seja ele a uma equipe que representa um clube ou um Estado-nação. Precisamos alargar o entendimento de como se produzem e se reproduzem os vínculos, em especial o de indivíduo-clube, do qual emerge uma categoria singular de pessoa, o torcedor, e os vínculos entre os clubes, dos quais emerge uma cartografia singular das identidades e das diferenças coletivas.

\section{2 - A circulação das emoções entre torcedores de clubes rivais}

É possível considerar um sujeito plenamente socializado para o futebol de espetáculo quando ele tiver experimentado as oscilações de- 
correntes do fato de pertencer a um clube de futebol. Seria dizer o mesmo afirmando-se que um torcedor sentirá a pleno o que significa torcer quando experimentar trocar de clube e perceber que isso é demasiadamente custoso ou, ainda, tentando gostar de outro, sentir-se tocado pelo antigo clube do coração. A fidelidade é estruturante no clubismo e seu amálgama é afetivo, por isso tão consistente e difícil de ser verbalizada pelos torcedores. Eles sabem que são fiéis a seus clubes e o dizem abertamente. ${ }^{18}$

As hipóteses daqui por diante são arrojadas. A primeira dá conta de que a fidelidade clubística é um valor arbitrário, mas que confere a este pertencimento uma especificidade. A pergunta é: como este valor foi constituído? A esta pergunta é oferecida a seguinte conjectura: a fidelidade é um valor indissociável à noção de pertencimento na medida em que cumpre, no clubismo, uma função estabilizadora. Sem esta estabilidade dos vínculos entre torcedores e clubes, o sistema não se sustentaria. Ou ainda, se os torcedores pudessem trocar de clube toda a vez que desejassem, não haveria como circular as emoções para além do espaço-tempo do jogo.

Esse raciocínio sugere, por seu turno, outra observação importante: há circulação de emoções clubísticas para além do espaço-tempo do jogo, sendo que as emoções vividas por ocasião do jogo possuem com elas estreita relação. De mais a mais, é a partir da compreensão da maneira como se articulam umas e outras que se pode avançar na compreensão da estética torcedora, conectando estas com outras emoções e, portanto, o futebol com outros fatos sociais e afetivos. A fidelidade é tomada como a constante no sistema clubístico. Ela determina que um torcedor mantenha-se informado acerca do cotidiano do time que representa seu clube para além do espaço-tempo ritual e assim conecta o ordinário e o extraordinário, os bastidores e o espetáculo, as discussões com as emoções e assim por diante. Além disso, a fidelidade não apenas possibilita a comunicação cifrada entre os torcedores, sobretudo no que tange às emoções - se você é gremista, então sabe o que sente um colorado quando o Inter perde ou ganha... -, senão que os posiciona no sistema: uma vez Flamengo, Flamengo até morrer. As implicações disso ver-se-ão em breve.

18 Não há demérito nisso, em que pese não seja de praxe os homens do futebol anunciarem outras modalidades de fidelidades - "pega mal". É mais ou menos generalizada a ideia de que, no Brasil, troca-se de "partido, de mulher e de religião, mas não se muda de clube de futebol". 
Para compreender a implicação que tem a fidelidade para o clubismo é preciso, em primeiro lugar, desvencilhar-se da ideia de que as emoções explicam-se por elas mesmas. Como afirma Le Breton, ${ }^{19}$

[...] les sentiments et les émotions ne sont pas des états absolus, des substances transposables d'un individu et d'un groupe à l'autre, ce ne sont pas, ou pas seulement, des processus physiologiques dont le corps détiendrait le secret. Ce sont des relations. Les perceptions sensorielles ou le ressenti et l'expression des émotions paraissent l'émanation de l'intimité la plus secrète du sujet, mais ils n'en sont pas moins socialement et culturellement modèles.

Desse modo, pode-se avançar afirmando que as emoções experienciadas no espectro do futebol não são irracionais, tampouco geradas espontaneamente ou aleatoriamente. Não são nem mesmo redutíveis às hipóteses psicologizantes, sobretudo aquelas que as explicam a partir do subterfúgio à regressão e à animalização "das massas" ou de outras reduções do gênero. ${ }^{20} \mathrm{O}$ pertencimento clubístico é uma espécie de máscara e implica uma transição de uma personagem a outra. Particularmente, implica a identificação de um indivíduo a dada coletividade e, portanto, uma transubstancialização de indivíduo a persona. Isso pressupõe, como afirma Rabain-Jamin, 'l'existence d'une ordre de symboles, d'une logique des représentations et d'un dispositif rituel qui lui assignent une place aussi bien qu'un rôle dans la société et lui assurent une reconnaissance [...]"..11

É-se Fluminense ou Vasco como se é comunista ou capitalista, disse Drummond. No entanto, para cada qual das incontáveis máscaras

19 Le BRETON, David. Les passions ordinaires. Paris: Armand Colin/Masson, 1998. p. 7. "Os sentimentos e as emoções não são estados absolutos, substâncias que se pode transpor de um indivíduo a outro. Elas tampouco são, ao menos não exclusivamente, processos fisiológicos cujos segredos estariam contidos no corpo. Trata-se de relações. As percepções sensoriais ou a sensação e a expressão das emoções parecem a emanação mais secreta do sujeito, mas isto não significa que elas não sejam socialmente e culturalmente modeladas." (minha tradução).

20 Para uma crítica sucinta, porém suficiente às tendências psicologizantes de senso comum aplicadas ao entendimento dos espetáculos esportivos ou de multidões, conferir EHRENBERG, Alain. Le culte de la performance. Paris: Hachette Littératures, 1991. p. 30-44.

21 RABAIN-JAMIN, J. Personne (verbete). In: BONTE, Pierre; IZARD, Michel. Dictionaire de l'Ethnologie et de l'Anthropologie. 2. ed. Paris: Quadrige/PUF, 2002. p. 571. 
que adotamos ou herdamos ao longo da existência, existe uma forma de herdá-las e em certos casos uma razão para existirem, assim como emoções compatíveis aos respectivos usos. O pertencimento clubístico com certeza não se encontra na ordem das necessidades biológicas ou instrumentais, quaisquer que sejam. Ainda assim, quase todos os brasileiros, sobretudo os homens, torcem por um clube de futebol, o que indica haver certo ônus em não se torcer por clube algum..$^{22}$ É preferível ser de alguém a não ser de ninguém, ao menos em se tratando de futebol. Não torcer por algum clube - o que seria o equivalente a não pertencer a ninguém - é ser um simples indivíduo, pois o pertencimento, pelo fato de integrar o sujeito a uma dada comunidade de sentimento, pessoaliza-o. Não torcer por clube algum é não usar uma máscara, o que efetivamente não acarreta qualquer sanção de ordem jurídica ou moral, apenas é ser ignorado, um "ninguém" em matéria de emoções e jocosidades clubísticas. Nesse particular, a maneira como os torcedores experimentam a transição de indivíduos a pessoas - ou de cidadãos a flamenguistas, por exemplo - é água para o moinho de DaMatta, quando este argumenta que não há nada pior para um brasileiro do que ser apenas um indivíduo..$^{23}$

A transição de indivíduo a pessoa, no caso do clubismo futebolístico, é algo que compete, primeiramente, à família, razão pela qual, suspeita-se, tornam-se as emoções futebolísticas, já na origem, indexadas a outro sistema de pertenças no qual o fluxo de emoções é igualmente intenso. Não há espaço para exemplos, com narrativas a este respeito, ${ }^{24}$ mas merecem ser reiterados alguns dados já referidos e comentados alhures, apoiados

22 Segundo pesquisa Datafolha de 2007, aproximadamente $26 \%$ dos brasileiros não torcem para nenhum time/clube. Disponível em: $<$ http://datafolha.folha.uol.com.br/po/ver_po.php?session=538>. Acesso em: 25/05/2012.

$23 \mathrm{O}$ argumento poderia romper as fronteiras nacionais, mas não cabe entrar neste debate por hora.

24 Suponho que meus leitores tenham, em seus circuitos de sociabilidade, pessoas - normalmente homens - que deem ao pertencimento clubístico razoável ou muita importância. Haverão de lembrar, então, caso estes adultos tenham filhos, netos, sobrinhos ou afiliados, de episódios ou narrativas em torno de um evento aparentemente banal: a primeira ida ao estádio do neófito. Mesmo sem ter trabalhado sistematicamente sobre o tema - razão pela qual partilho minhas impressões - os depoimentos de que disponho dão conta de que este é um evento dramático para a relação entre pai-filho, tio-sobrinho, padrinho-afiliado e assim por diante. Os adultos possuem, via de regra, constrangimentos em revelar publicamente a meticulosidade com que operam a escolha do jogo ao qual o neófito será apresentado ao clube pelo qual ele já deve pertencer, por opção do adulto. E se o time perder? Será que ele não vai se frustrar e querer mudar de clube? Mas se não for levado de uma vez, não haverá o risco de ele interessar-se pelo clube rival? 
em pesquisa realizada no âmbito de Porto Alegre. ${ }^{25}$ Em praticamente $70 \%$ dos casos, a escolha do clube, dito do coração, fora feita por influência da rede de sociabilidade familiar - avô, pai, irmão, tio, primo, sobretudo - ou muito próxima a ela - padrinho e amigos de infância e/ou adolescência. Ninguém nasce palmeirense ou flamenguista, mas não são raros os que assim se declaram. É o caso dos proselitizados na primeira infância, quase sempre meninos, filhos, netos, irmãos menores ou afilhados de um torcedor fanático. A mesma pesquisa indica que as escolhas clubísticas, ao menos entre os porto-alegrenses, ocorrem até os 10 anos de idade para aproximadamente $70 \%$ dos casos - quase a metade dos entrevistados disseram ter feito a escolha antes dos cinco anos de idade, o que está claro que foram, antes de mais nada, escolhidos. À época em que a pesquisa foi realizada, 1996, 10\% dos entrevistados declaravam ter mudado de clube, sendo que mais de $85 \%$ afirmaram que não mudariam "jamais".

A hipótese de que a fidelidade clubística pudesse ser um desdobramento das afinidades parentais levou-me a traçar alguns mapas cruzando parentesco e pertencimento clubístico, entre os meninos e meninas da Leão XIII, meus informantes ao longo da pesquisa visando à tese. ${ }^{26}$ Em 80 casos de descendência paterna em $1^{\circ}$ grau, pai/filho ou filha, nos quais havia indicação de pertença - nem todos os informantes souberam indicar os clubes pelos quais torcem sua parentela mais distante -, houve 67 coincidências e 13 incompatibilidades entre pai e filho ou filha. Ou seja, para cada cinco descendentes que seguem a predileção paterna, ao menos um destoa. No entanto, se considerarmos o universo possível de clubes para quem torcer, o fato de que $80 \%$ dos filhos acompanhem a preferência do pai e mais de $30 \%$ dos netos a do avô paterno é um dado notável.

No caso do Brasil, as identidades clubísticas são clivadas pelos regionalismos. A dupla Gre-Nal detém índices elevados de preferência entre os sul-rio-grandenses e, sobretudo, entre os porto-alegrenses, caracterizando o Estado e a cidade como os mais "bairristas" do Brasil. ${ }^{27}$ Como

25 DAMO, Arlei. Para o que der e vier..., 1998, p. 75-85.

26 DAMO, Arlei. Do dom à profissão..., 2005, p. 87-88.

27 Seguindo os dados da pesquisa Datafolha de 2007, observamos que em torno de $84 \%$ dos habitantes do Rio Grande do Sul torcem por clubes sediados no próprio Estado, sendo que este índice alcança 91\% em relação à cidade de Porto Alegre. Para mais informações consultar o endereço: <http:// datafolha.folha.uol.com.br/po/ver_po.php?session=538>. Acesso em: 25/05/2012. 
as preferências se concentram em apenas dois clubes - e se distribuem quase equanimemente entre eles -, os percentuais de fidelidade na transmissão do pertencimento tendem a ser supostamente mais elevados do que em outros Estados ou cidades. Nos Estados onde existem mais clubes ou onde os clubes locais não têm muita expressão nacional, esses percentuais tendem a se dissipar. Ainda assim é desconcertante observar o tanto que o parentesco interfere não apenas na escolha do clube, mas também na forma como a sensibilidade dos neófitos é moldada.

$O$ fato de a escolha do clube ser influenciada preferencialmente por um parente consanguíneo do sexo masculino levou-me à formulação da hipótese de que a fidelidade clubística pudesse estar relacionada ao valor simbólico atribuído aos laços de sangue, tão presentes no parentesco. Dadas as influências da parentela consanguínea no acesso ao clubismo em geral, e na escolha de um clube em particular, o pertencimento clubístico poderia ser tomado enquanto uma espécie de tradução das afinidades de sangue. O pertencimento seria inquebrantável, pois assim é que são pensados, do ponto de vista da nossa cultura, os laços de sangue, como sugere Schneider. ${ }^{28}$

Outro dado interessante é o englobamento das mulheres nos casos de matrimônio. Nessa mesma pesquisa, realizada por ocasião da tese, e em outras ocasiões em que retomei esta questão, ficou evidente a incorporação das mulheres pelos maridos para os casamentos das gerações mais antigas. É evidente que isso ocorre nos casos em que o pertencimento delas não é entusiástico - salvo uma exceção, ao menos, em que a vovó "saiu do armário" depois da morte do marido -, ou seja, em que não há interesse pelas coisas do futebol e, particularmente, pelo clubismo. Poder-se-ia afirmar, ainda, que assim como é cada vez menor a tendência de as mulheres incorporarem o sobrenome da família do marido por ocasião do casamento, ou não mais suprimirem a identificação com a família de origem nas mesmas circunstâncias, também é menos frequente a mudança de pertença clubística. Poder-se-ia conjecturar, finalmente, que dada a fle-

28 'What are called 'blood ties' can be understood as the bonds of solidarity that are caused by or engendered by the actual biological connectedness, sometimes figured as genetic, sometimes hereditary, sometimes in emotional terms. Or the notion of blood can be understood as figurative, iconic, but still attending for the bonds of solidarity, bonds which are deeply affective, deeply binding, actually breakable but to be broken under the most unusual, tragic, unforgivable circumstances". SCHNEIDER, David M. Conclusion. In: . A critique of the study of Kinship. Ann Arbor, Michigan: The University of Michigan

Press, 1992. p. 195. 
xibilização das diferenças dos papéis sexuais, a tendência é encontrar cada vez menos mulheres dispostas a abrir mão do que quer que seja, mesmo de uma herança aparentemente frívola, como é o pertencimento clubístico. $\mathrm{O}$ fato é que esses casos de englobamento da esposa pelo marido ainda são frequentes, enquanto o inverso é, francamente, um tabu - ao menos não registrei nenhum caso até o presente.

O englobamento das mulheres, a reprodução das pertenças por três ou às vezes mais gerações de consanguíneos do sexo masculino, além de os ritos de convencimento serem frequentemente dirigidos pelos homens - pai, avô, irmão etc. - e tanto mais cuidadosamente orquestrados para seduzir os meninos em relação às meninas, sobretudo quando o adulto declarar-se torcedor passional, além de outros fatos observáveis no cotidiano, levaram-me a formular uma nova hipótese. Segundo ela, a proeminência masculina na prática do futebol e nos estádios, assim como em quase tudo o que diz respeito a este esporte, exceto, talvez, o interesse pela seleção nacional, que corre à margem do clubismo - operando a partir das pertenças ao Estado-nação -, seria uma espécie de residual do patriarcado. Antes de responder afirmativamente à hipótese de que o patriarcado sobreviveria disfarçadamente sob a pele de um espetáculo moderno, convém ampliar e diversificar a amostragem, o que está fora do alcance dessa investigação. Entretanto, a aproximação do clubismo com o parentesco permite compreender as razões pelas quais os machos empenham-se em reproduzir seus pertencimentos clubísticos entre os consanguíneos, aqueles a quem o valor atribuído aos laços de sangue indica uma solidariedade inquebrantável. Com os filhos, os netos, os irmãos e os sobrinhos espera-se viver junto os altos e baixos atinentes às disjunções futebolísticas.

Já se disse que o pertencimento é uma máscara herdada quase sempre de um parente consanguíneo do sexo masculino e que a partir dela o torcedor não pertencerá apenas a uma comunidade de sentimento imaginada, mas a um sistema integrado por várias comunidades, definido aqui como clubismo, dentre elas aquela a quem lhe será ensinado a gostar e outra que haverá de aprender a desdenhar. Ou seja, um pai tende a tornar seu filho palmeirense, como ele, mas é o sistema de pertenças que fará, a ambos, desdenharem os corintianos. Na prática, os processos são, via de regra, simultâneos e é esta "outra face" do clubismo, aquela do desdém, 
do ódio, do chiste e das jocosidades, que será aqui destacada, pois ela distingue a circulação das emoções futebolísticas de outras modalidades de sociabilidade. Além da identidade, através do clubismo vive-se a alteridade.

Um jogo de futebol é um evento produtor de disjunção e toda a disjunção implica possibilidades antitéticas: vitória/derrota, êxito/fracasso e assim por diante. A cisão entre perdedores e vencedores tem como função desestabilizar temporariamente o sistema. Ou ainda e numa só palavra: a disjunção dinamiza o clubismo. Herdar a pertença significa habituar-se a sentimentos de alegria quando o time vence e de entristecimento ou enfurecimento quando ele perde, mas a persona clubística é igualmente estimulada a alegrar-se com a derrota do arquirrival e a calar diante de seu êxito. Rejeitar estas trocas é negar-se a viver a alteridade proposta pelo clubismo e, portanto, negar-se a participar de um potente circuito de jocosidades com forte conotação afetiva.

A alegria, a tristeza, a dor, a excitação, o êxtase, a ira e a desolação, entre outros sentimentos próprios aos torcedores, são expressos claramente, seja no estádio ou fora dele. São expressões obrigatórias, como diria Mauss, ${ }^{29}$ na medida em que se complementam, pois, sendo antitéticas, umas e outras estão completamente imbricadas. A dor dos gremistas é o combustível da alegria colorada, razão pela qual aprender a amar o Inter é tão importante quanto detestar o Grêmio e o processo de socialização torcedora inclui tal sensibilidade. A incorporação dos dispositivos de amor e de ódio diante da derrota e da vitória, tanto quanto em relação a um "nós", representado pelo clube/time amado, e a um "outro", identificado com o clube/time rival, é um processo gradativo, de educação sentimental, pois a expressão pública desses insultos envolve algumas regras em relação a espaços, tempos, pessoas e, sobretudo, certo autocontrole acompanhado de humor, sarcasmo, ironia e criatividade.

Se observadas com atenção, nota-se que as trocas de insultos ordinários (jocosidades) entre os torcedores rivais não são da mesma ordem daquelas processadas em circunstâncias rituais. Os insultos ordinários são relativamente amenos e assemelham-se sob vários aspectos, incluindo-se o

29 MAUSS, Marcel. A expressão obrigatória de sentimentos. In: ; CARDOSO DE OLIVEIRA, Roberto (Org.). Ensaios de Sociologia. São Paulo: Ática, 1979, p. 147-53. [Col. Grandes Cientistas Sociais]. 
tom ambíguo entre a hostilidade e a amistosidade, ao que Mauss, seguindo M. Radin, denominou de joking relationships ou "parentesco por brincadeira". ${ }^{30}$ É importante retomar Mauss pelas possibilidades que seu artigo sugere, dentre as quais a vinculação do parentesco por brincadeira com os sistemas de prestações totais e, particularmente, com os rituais de trocas agonísticas, em que se destaca, evidentemente, o potlatch. Preocupado sempre com o concreto, Mauss dirá que cada sociedade tem seu próprio parentesco por brincadeira, mas ele também sugere comparações que de resto não devem ser compreendidas senão a partir dos fluxos: quem brinca com quem, quais as regras de etiqueta, quais são os tabus, quais os termos lícitos, ilícitos, preferenciais e assim por diante.

E qual seria, afinal, a modalidade preferencial de jocosidade veiculada nas trocas clubísticas? Gracejar talvez seja um termo demasiadamente polido para expressar as brincadeiras entre torcedores rivais. Preferem os homens, que de resto são os que mais apreciam estas trocas, termos como "gozar", "tirar sarro", "arriar-se", "deitar-se", "judiar", "pegar no pé” e outros do gênero, quase todos ambíguos, com indisfarçável conotação sexual. No estádio, um colorado xingará a todos os gremistas, mas fora dele só gozará os (nos) que pertencem a sua rede de sociabilidade, normalmente a mais próxima ou intensa - amigos, parentes, colegas de trabalho, vizinhos e assim por diante. Fazem piadas, perguntam pelo resultado de um jogo que já sabem, insinuam, riem, enviam torpedos, vão ao trabalho com a camiseta do clube (com um brinco, um boton, um adereço qualquer), enfim, há mil e uma possibilidades de exibir-se, de provocar, de gozar o outro. Entretanto, são sobretudo as metáforas sexuais as moedas principais que circulam pelas redes de homossociabilidade. Como tais jocosidades são lícitas aos olhos do clubismo, o porteiro goza o (no) condômino, e vice-versa, sendo que nesses

30 MAUSS, Marcel. (1926). Parentes à plaisanteries. In: Oeuvres. v. II. Paris: Éditions de Minuit, 1969. p. 109-25. Na esteira de Mauss, Radcliffe-Brown deu ao parentesco por brincadeira uma roupagem funcionalista, o que não retira sua atualidade. "O parentesco por brincadeira é uma combinação peculiar de amistosidade e antagonismo. O comportamento é tal que em qualquer outro contexto social exprimiria e suscitaria hostilidade; mas não é entendido seriamente e não deve ser tomado de modo sério. Há uma pretensão de hostilidade e real amistosidade. Em outras palavras, o parentesco é o do desrespeito lícito. Assim, qualquer teoria completa sobre ele deve ser parte de uma teoria do lugar do respeito nas relações sociais e na vida social de modo geral. Mas este é um problema sociológico muito amplo e importante; porque é evidente que toda manutenção da ordem social depende do adequado tipo e grau de respeito para com certas pessoas, coisas, idéias ou símbolos". RADCLIFFE-BROWN, Alfred. Os parentescos por brincadeira. In: Estrutura e função na sociedade primitiva. Petrópolis: Vozes, 1973. p. 116. 
casos de clara assimetria de status o fluxo tende a ser iniciado pelo torcedor de status mais elevado. Ao gozar "o" ou "no" torcedor arquirrival, abre-se a possibilidade de vir a ser gozado ou, preferindo-se, está se autorizando uma modalidade peculiar de comunicação. A licenciosidade instaurada pelas jocosidades clubísticas faz do futebol um poderoso dispositivo de sociabilidade transversal, rompendo diversas hierarquias e categorias sociais, tais como: pobre/rico, negro/branco, criança/adulto, mulher/homem e assim por diante.

Algumas regras são importantes para que os fluxos sejam regulares e permanentes. Pode-se não gostar de futebol; detestá-lo, inclusive. Nesse caso, o sujeito estará fora desse universo, não havendo risco de ser insultado por nenhum amigo ou subordinado, à exceção, é claro, se tiver o azar de cruzar com torcedores a caminho do estádio - eles xingam indiscriminadamente todos os que não compartilham com eles o êxtase do pertencimento, quer dizer, dos que não estão dispostos a brincar, a entrar para o mundo da fantasia. O que o sistema não tolera, de modo algum, é a ambivalência: a) daquele que ora gosta, ora não gosta de futebol; b) daquele que ora torce por um clube, ora por outro. Ambos não são bons para se brincar, pois eles não permitem a circulação - quer dizer, o dar e o receber - das gozações, não se conformando aos princípios elementares das identidades e alteridades sugeridas pelo sistema.

Se você é Inter e o Inter ganha, então você tem o direito a dar uma gozada no seu colega gremista. Se o Inter perde, tem a obrigação de receber, preferencialmente calado e de forma amistosa, para que quando o Inter vencer lhe seja permitido retribuir a gozação. Negar-se a ser gozado é negar-se a receber e, como tal, negar-se a participar das trocas, o que pode vir a ser tomado como falta de compostura - de espírito de humor, leveza, amenidade, jogo de cintura etc. Assim, chega-se à compreensão, por uma segunda via, das razões pelas quais o pertencimento é imutável. Se fosse permitido mudar de clube, não haveria como impedir que um torcedor o fizesse a toda hora, conforme a conveniência. O clubismo, por extensão, ruiria imediatamente. Se você é Inter e o seu time vence, você pode tomar a iniciativa de fazer a piada, de pôr o sistema em circulação, de insultar a honra dos gremistas, especialmente quando o time deles foi derrotado pelo seu. Isso implica, de um ponto de vista posicional, tornar-se ativo/passivo. E o que é notável: é o seu time quem lhe torna ativo ou passivo. Pela performance dele é que alguém terá o direito a fazer ou o dever de receber uma jocosidade; de gozar 
em ou ser gozado por alguém. Talvez por isso o sofrimento faça parte da rotina de quem se diz torcedor, dos homens em particular, afinal, ser torcedor é tornar-se susceptível de vir a ser passivizado metaforicamente.

Como o clubismo e, sobretudo, os fluxos jocosos cotidianos mobilizam preponderantemente o público masculino, mas não exclusivamente, não há como cegar em relação às possibilidades de transcender o campo do futebol em direção à sexualidade; ou de tramá-los, quem sabe. Se pertencer é correr o risco de ser insultado, gozado e passivizado, seria lógico pressupor que o sistema haveria de sugerir a interdição de certos fluxos, afinal, a nossa cultura impõe determinados tabus sexuais. $\mathrm{O}$ fato de herdar o pertencimento de um familiar ou amigo muito próximo à família não seria justamente o mecanismo que impede o fluxo jocoso entre aqueles a quem outro sistema simbólico, no caso o parentesco, interdita esta modalidade de trocas?

Há, efetivamente, certa lógica nisso, afinal, o que se percebe, concretamente, é que o pai que não se empenha em fazer do filho mais um membro da sua comunidade de pertença certamente não é alguém que se importe verdadeiramente com o clubismo. Ou, por outra, trata-se de alguém para quem pouco lhe interessa o futebol e, sobretudo, alguém para quem as jocosidades atinentes ao clubismo não lhe sensibilizam, razão pela qual jamais gozará e, por extensão, dificilmente será gozado por alguém. $\mathrm{Na}$ hipótese de que o filho viesse a se tornar um torcedor fanático, as possibilidades de fluxos jocosos entre eles estariam de qualquer modo descartadas. Em sentido inverso, é o torcedor dito fanático, aquele que vive o clubismo a pleno, o protótipo do proselitista. Se entendermos as gozações, dado o seu duplo sentido, como interditas a certas classes de relações, reencontramos então uma segunda razão para a tendência, dos consanguíneos masculinos anularem a possibilidade de jocosidades entre eles, fazendo com que seus descendentes herdem-lhes a predileção clubística. Dizendo um tanto simplificadamente, o clubismo permite que se goze o patrão, a autoridade, o ricaço e quem quer que se permita, mas não o pai e o irmão, nem o pai do pai, nem os irmãos do pai, nem os filhos dos irmãos do pai, nem os amigos que se quer tanto quanto se fossem irmãos, enfim, preservam-se aqueles com quem se possui laços de sangue, reais ou inventados.

Essas são hipóteses arrojadas. Cabem, portanto, ponderações, a primeira delas reforçando, uma vez mais, a necessidade de complementá-las com dados empíricos, corroborando-as ou refutando-as. Não vem ao 
caso detalhar a maneira como elas poderiam ser testadas, mas isso não é apenas possível, senão que desejável. De outra parte, é preciso ressaltar que a procura por regras e sentidos ocultos não é o fim último da antropologia, razão pela qual o que justifica conjecturas como as que foram aqui realizadas é a importância do sistema de pertenças para a compreensão do futebol de espetáculo.

\section{Finalização}

Nem todos os que se declaram torcedores são do tipo "fanático", "doente", "maluco", enfim, aqueles para quem o clubismo efetivamente importa. Assim sendo, existe uma plêiade de possibilidades de se fruir um espetáculo futebolístico, mas é indiscutível que ele só chegou a ser o que é graças à militância dos torcedores pelos seus clubes, razão pela qual não se pode compreender o espetáculo sem olhar para as razões daqueles que o sustentam emocional e engajadamente. E espero não ter deixado a impressão de que se vai ao estádio para torcer por um time a fim de evitar que o pai (o filho, o avô, o próprio torcedor etc.) seja passivizado metaforicamente por meio das jocosidades do dia seguinte. Porém, são os tipos libidinosos - no sentido de libido, desejo, paixão, luxúria -, completamente envolvidos na e pela trama das pertenças que fazem o futebol ser diferente de outros esportes no Brasil. E é por essa razão que se atribui aqui tanta importância ao clubismo e ao pertencimento, sendo este último o elo afetivo capaz de dragar os indivíduos para um universo no qual são instigadas as alteridades de quase todas as espécies.

O pertencimento produz illusio, como uma modalidade de adesão ao jogo quase absoluta e que é produto do jogo ao mesmo tempo em que é condição de seu funcionamento. A noção de illusio tem por referência as considerações de Bourdieu sobre o funcionamento do campo da política, mas o ponto de partida para tal analogia, bem como para a adoção de uma dada perspectiva estética sobre os futebóis, que marca a "versão do autor", é certamente aquela passagem de Drummond referida no início deste texto. Sem a obrigação de segui-lo integralmente, reproduzo a passagem em que consta o essencial para o entendimento da noção bourdiana de illusio e, 
por extensão, da vinculação do clubismo com a participação engajada na política, um certo partidarismo, quem sabe.

\begin{abstract}
Nada há que seja exigido de modo mais absoluto pelo jogo político do que esta adesão fundamental ao próprio jogo, illusio, involvement, commitment, investimento no jogo que é produto do jogo ao mesmo tempo que é a condição do funcionamento do jogo: todos os que têm o privilégio de investir no jogo (em vez de serem reduzidos à indiferença e à apatia do apolitismo), para não correrem o risco de se verem excluídos do jogo e dos ganhos que nele se adquirem, quer se trate do simples prazer de jogar, quer se trate de todas as vantagens materiais ou simbólicas associadas à posse de um capital simbólico $[\ldots] .^{31}$
\end{abstract}

A illusio é condição para se compreender aquela que talvez seja a razão pela qual o futebol é um espetáculo diferenciado: a excitação diante do risco e, portanto, do medo de ser gozado, de ser passivizado, de ser subjugado pelo outro que, via de regra, está próximo - como gremistas e colorados, avaienses e figueirenses, atleticanos e coritibanos, entre outros. Não menos importante é a excitação de partilhar os afetos, algo que os homens podem fazer entre eles e em público. Os estádios não são propriamente públicos, nem privados. Em geral, são frequentados por pessoas acompanhadas e afetivamente próximas. Pode-se também optar por lugares nos quais o pertencimento é partilhado com mais facilidade, como nas gerais, frequentadas pelas camadas populares, cuja expressão dos sentimentos clubísticos é notadamente efusiva, talvez porque a educação dos sentidos faculte-lhes certo autocontrole a que estão submetidos os modernos. Porém, não há nada mais triste do que estar só em meio à multidão.

Por mais primárias que se revelem as emoções torcedoras, há sempre um sistema simbólico a orientá-los. Falta-nos avançar e mostrar, a partir de casos concretos, como se produzem, nos estádios de futebol e fora deles, por ocasião de jogos ou não, certas modalidades de comportamento que, se não são únicas, são, no entanto, peculiares. Nos estádios, por exemplo, são permitidas certas manifestações que ordinariamente não seriam toleradas, pois, assim como o templo é o lugar da prece, o estádio é a tribuna dos insultos, e ambos 
são bons para se compreender quem são aqueles que os dizem. O pressuposto de que o público do futebol é engajado é um ponto de partida e possui consequências mais amplas do que se poderia supor em um primeiro momento.

Pensada em termos exclusivamente financeiros, a paixão clubística é um péssimo negócio, pois os torcedores nada podem esperar como retribuição. Sob a égide do profissionalismo, regime econômico e jurídico vigente na atualidade, os jogadores ganham mesmo quando o time perde, ao passo que os torcedores perdem mesmo quando o time ganha, afinal o dinheiro empenhado - direta ou indiretamente - não é jamais retornado. Além do dinheiro, o tempo é outra modalidade de bem empenhado pelos torcedores. Se, em relação ao dinheiro, pode-se afirmar que eles perdem quando dão, acerca do tempo deve-se ressaltar que seu empenho está envolto pela noção de risco, afinal, não há garantias de que uma tarde de domingo gasta num estádio seja sinônimo de prazer. Por essas e outras, não se pode pensar no interesse pelo futebol de espetáculo como algo restrito àquilo que se passa dentro de campo, ao jogo propriamente dito.

Como o futebol é coletivo, a tarefa de representação recai sobre um time, e não sobre um indivíduo. Em todo o caso, os times mudam muito rapidamente e o apreço que os torcedores têm por eles também. Os clubes, ao contrário dos times, geralmente possuem uma longa trajetória, alguns de mais de um século. Eles desafiam a duração e, por isso mesmo, permitem uma identificação duradoura. $\mathrm{O}$ fato de que os torcedores cantam o hino dos clubes, numa prova de identificação inquestionável, mesmo quando as performances do time são tão ruins que acabam rebaixando o clube, ilustra este a dimensão sagrada e a solidez da identificação.

Do ponto de vista antropológico, o clubismo pode ser definido como um sistema de representações que opera à maneira do totemismo, do nacionalismo, do partidarismo ou de qualquer outro sistema no qual a unidade básica à qual o indivíduo se vincula é posta em relação com outras unidades. Embora a analogia precedente possua implicações profundas, sobretudo do ponto de vista teórico, um destaque é suficiente para a continuação do argumento. O clubismo é um sistema de representações estruturado, de forma que o indivíduo, ao tornar-se torcedor, é capturado por códigos que orientam seu comportamento e moldam sua sensibilidade. Não convém exagerar no peso coercitivo deste sistema, mas é fato que ele funciona a pleno quando as regras são respeitadas. Isto implica dizer que alguém que se tornou torcedor do Barcelona deverá se opor, pelas regras 
de afinidade do sistema, ao Espanhol (rivalidade circunscrita à Cataluña) e ao Real Madrid. Na maior parte dos casos, o sistema opera tendo no ponto de partida uma díade - uma rivalidade arquetípica -, mas não são raros os casos em que três e até quatro clubes podem compor a base das afinidades.

A sugestão de pensar o clubismo como uma modalidade de totemismo visa, fundamentalmente, destacar a importância da dimensão simbólica e, particularmente, ao fato de que a ênfase da contribuição de Lévi-Strauss, autoridade indiscutível nesta questão, recai sobre a relação entre as partes. Quer dizer que, além de destacar a importância fulcral da noção de pertencimento clubístico, ganha-se em compreensão de como pensam os torcedores quando se leva em conta o fato de que o pertencimento a um clube implica o pertencimento a um sistema de relações. Este sistema não é menos real pelo fato de sua existência ser preponderantemente simbólica, dado que as emoções, facilmente observáveis no plano empírico, são constituídas simbolicamente. Sem compreender a história de uma rivalidade não há como atribuir sentido à segmentação de público e, sobretudo, às hostilidades que permeiam a relação entre esses segmentos. Sob certo aspecto, e esta talvez seja a consideração mais importante a este respeito, a relação entre os clubes - ou, preferindo-se, as rivalidades e as lealdades - tem uma natureza simbólica parcialmente descolada do mundo empírico, na medida em que, tanto aqui como no âmbito da nação, as tradições são inventadas.

Em todo o caso, a compreensão da história das rivalidades não pode seguir o curso da historiografia convencional. O que é fundamental de reconstituir, tanto quanto possível, é o processo de adensamento simbólico das disputas, considerando não apenas os dados factuais - jogos, gols, artilheiros etc. -, mas a história sentimental. Claro que as questões suscitadas pelo imaginário do clubismo se atualizam concretamente, por ocasião das disputas propriamente futebolísticas. Quando foi dito que o clubismo, enquanto um sistema de crenças e de sentimentos, tem certa autonomia em relação aos acontecimentos factuais, não se imaginou um descolamento completo. Antes, pretendeu-se enfatizar que, tão ou mais importante do que os lances de um jogo, é a experiência de tê-los vivido que importa efetivamente aos torcedores.

Recebido em julho de 2012. Aprovado em agosto de 2012. 